\title{
Relationship between Socio-Demographic Factors and Eating Practices in a Multicultural Society
}

\author{
Stephanie M. Krige ${ }^{1}$, Fawzi M. Mahomoodally ${ }^{1 *}$, Anwar H. Subratty ${ }^{1}$, Deerajen Ramasawmy ${ }^{2}$ \\ ${ }^{1}$ Department of Health Sciences, Faculty of Science, University of Mauritius, Reduit, Mauritius; ${ }^{2}$ Department of Management, Fac- \\ ulty of Law and Management, University of Mauritius, Reduit, Mauritius. \\ Email: *f.mahomoodally@uom.ac.mu
}

Received November $23^{\text {rd }}, 2011$; revised January $14^{\text {th }}, 2012$; accepted January $21^{\text {st }}, 2012$

\begin{abstract}
There is currently a dearth of information pertaining to socio-demographic factors and eating practices in a multicultural country like Mauritius. This study was therefore undertaken to probe the different eating practices among an adult sample population in Mauritius in an endeavor to establish significant relationships, if any, with common socio-demographic and socio-economic factors. A self-designed questionnaire, (randomly distributed to $n=387$ adults), pertaining to socio-demographic variables, vegetarianism, breakfast patterns, eating out of home meals (OHMs), food frequency questions and dieting practices were asked. Males $(21-40 \mathrm{yrs})$ had a significantly $(p<0.05)$ higher consumption of $\mathrm{OHM}$ at lunch. Higher mean frequencies of consuming OHMs were found amid specific groups (e.g. amongst professionals as compared to each of manual workers, unemployed, retired and self-employed) which also depicted significantly lower percentages of adhesion to the WHO recommended daily intake of vegetables. Oily foods were frequently consumed by males $(41-60 \mathrm{yrs})$ whereas none of the socio-demographic factors assessed revealed a significant relationship $(p>0.05)$ to adherence to the recommendations for the consumption of fish. The socio-demographic factors most influential towards eating practices were gender, age and socio-economic status represented by education and occupation. In conclusion, relationships recorded in the present study were comparable to Western eating practices and the availability of certain foods has compelled Mauritians to develop its own and unique eating patterns which can be of relevance in providing accurate health targets for future nutrition interventions in Mauritius.
\end{abstract}

Keywords: Sociodemographics; Eating Practices; Out of Home Meal; Socio-Economic; Mauritius

\section{Introduction}

Sociodemographics, the study of people in society [1] include factors such as gender, age [2], household income and education level [3] among other factors. In society, there are different levels of education and income, and thus a plethora of social economic status (SES) exists. Sociologists refer to the classification of society into different classes as social stratification and due to which there are inequalities that exist in society [4]. These factors have also been documented to have an impact on lifestyle practices, including diet, which in turn determine health. This is why diet is included among the lifestyle practices which determine health [5].

Eating practices are important factors to consider in public health nutrition as people eat every day and throughout the day. Therefore, observing dietary practices may give an idea of the nutritional status of individuals in the population. In addition, certain eating practices may predict future health problems, such as high fast food consump-

"Corresponding author. tion and obesity as in US [6] Other practices may be a form of prophylactic for certain diseases such as postulated in the French paradox. Studying eating practices within a population is complex due to the multiplicity of different factors which are involved in the process of choosing, acquiring, preparing and consuming food as demonstrated by Baranowski [7].

While the number of non communicable diseases (NCD) is on the rise, where-by Mauritius has not been spared [8] there is a continuous need to amass updated information on the underlying nutritional causes with respect to these diseases. Worldwide, there have been significant relationships found between socio-demographic profiles and certain eating practices. For instance, Europeans from lower SESs tend to eat less healthily than those from higher socioeconomic background [5]. In addition, high income has been shown to increase BMI [9] and concern for food safety has been related to socio-demographic factors such as ethnicity, age and gender [10].

In view of the fact that there is a dearth of data pertaining to socio-demographic factors and eating practices 
in a multicultural country like Mauritius, this research was therefore designed and geared to gather relevant information on the topic. We also aimed at investigating the different eating practices in a representative adult sample population of Mauritius and to establish significant relationships and/or differences, if any, between these eating practices and common socio-demographic and socio-economic factors.

\section{Methods}

\subsection{Questionnaire Design}

The tool used to conduct the survey was a self designed questionnaire which was divided into different parts and adapted from Siega Riz, et al. [11], and Anderson and Morris [1]. A validated food frequency table was also inserted that covered questions about the 11 major food categories and the answers as described previously [5].

\subsection{Sampling}

A pilot study of about 20 questionnaires was conducted and appropriate changes were made accordingly. The study conducted was a cross sectional study of the Mauritian population amongst adults aged 21 years and above. According to the recent Mauritius Central Statistic Office census, this population size totalled to 831,482 . Based on Krejcie and Morgan, [12] a sample size of 384 was needed to represent a cross-section of the population at a $95 \%$ confidence level, a $\pm 5 \%$ margin of error and a 0.5 degree of variability. The sampling was conducted randomly at different locations of the Island, both urban and rural.

\subsection{Data and Statistical Analysis}

Data collected was analysed using SPSS version 16.0 and graphs were generated using Microsoft excel version 2007. $\chi^{2}$ tests, $t$-test and ANOVA were performed and $p$ values of $<0.05$ were considered significant.

\section{Results}

\subsection{Eating Home-Made versus Out of Home Meals}

The information gathered concerning the types of meals consumed at lunch and dinner was grouped into two categories: home-made meals and out of home meals (OHMs). The numbers of days per week were categorized into three groups: "never", "3 times per week or less" and "more than 3 times per week". The resulting percentages are depicted in Figure 1.

Data presented in Figure 1 demonstrates that the majority of respondents reported "never or seldom" eating OHMs both for lunch (52\%) and dinner (69\%). Eating out for dinner "4 - 7 times per week" was five times less than eating out for lunch at the same frequency. Likewise, eating out "1 - 3 times per week" was greater for lunch than for dinner. Hence, in general, a higher frequency of OHMs for lunch was reported (33\% and 15\%) as compared to dinner (26\% and 5\%).

Table 1 shows that there was significant difference for both gender and place of residence with respect to the consumption of OHMs. The mean consumption of OHMs was higher in men than women at lunch and higher amongst rural than urban inhabitants at dinner. It was also found that the mean consumption of OHMs was significantly higher in young adults than in middle aged and elders, for both lunch and dinner. The mean consumption of OHMs was significantly different in tertiary educated respondents only for lunch. And significantly different to secondary educated respondents for dinner; tertiary educated respondents having the higher means. There was a significant difference in the mean consumption of OHMs amongst professionals as compared to each of manual workers, unemployed, retired and self-employed respondents.

\subsection{Food Frequency Table}

The WHO/Europe (2011) for a healthy lifestyle has the following dietary recommendation:

1) Eat breads, grains, pasta, rice or potatoes several times per day.

2) Eat a variety of vegetables and fruits, preferably fresh, and local, several times per day (400 g).

3) Control fat intake (not more than $30 \%$ of daily energy) and replace most saturated fats with unsaturated vegetable oils or soft margarines.

4) Replace fatty meats and meat products with beans, legumes, lentils, fish, poultry or lean meat.

5) Use milk and dairy products that are low both in fat and salt.

6) Select foods that are low in sugar, and eat refined sugar sparingly, limiting the frequency of sugary drinks and sweets.

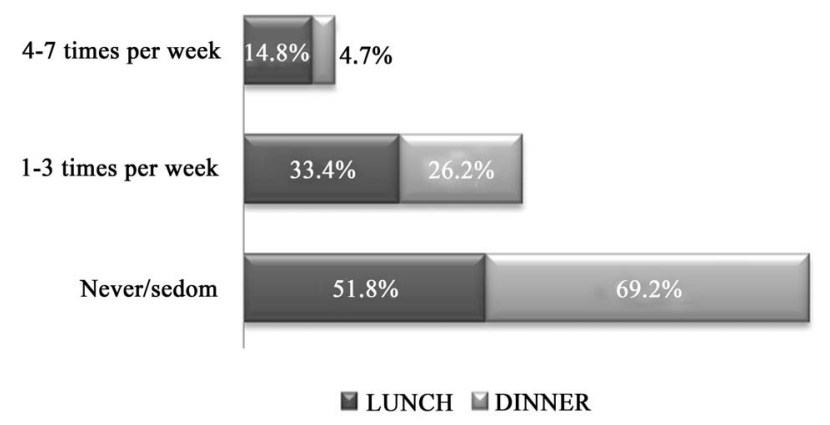

Figure 1. Frequency of eating OHMs with respect to lunch and dinner. 
Table 1. Mean difference of consuming OHMs with respect to gender and place of residence using Independent sample $t$-test and the mean difference in consuming OHMs for lunch and dinner using One-way ANOVA test.

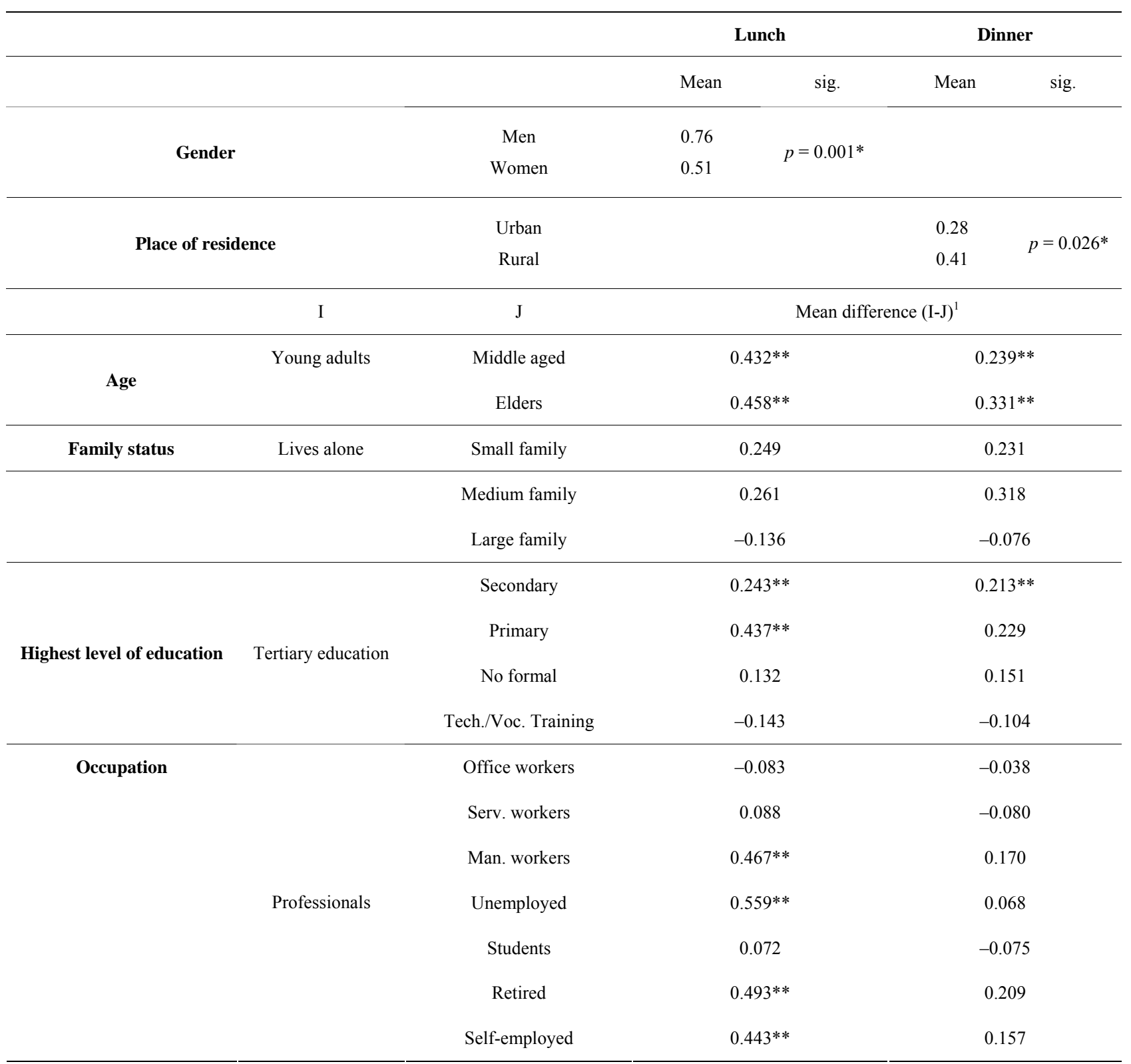

${ }^{1}$ One-way ANOVA test; ${ }^{*} p<0.05$ for Independent sample $t$-test; ${ }^{* *} p<0.05$ for One-way ANOVA test.

The guidelines above are represented in Table 2 along with the food item associated to each one of the guidelines. Scores of 1 or 0 were given to respondents adhering or non-adhering to the guidelines respectively.

The data collected was further analysed and depicted in Tables 3(a)-(b). Table 3(a) shows a significant relationship between meat intake and gender. The percentages of adherence to the recommendations of the WHO, in both men and women were $94.9 \%$ and $98.6 \%$ respectively. Although both percentages were considerably high, women adhered more than men. The intake of deep fried and fried food intake was significant with respect to both gender ( $p$
$=0.001)$ and place of residence $(p=0.001)$. A higher percentage $(81.8 \%)$ of women adhered to the recommendation for deep fried and fried food as compared to men (67.4\%). These figures were considerable despite the ratio of men to women in the sample. The place of residence, the percentages for urban and rural inhabitants were $16.7 \%$ and $31.1 \%$ respectively, for the frequency of "more than once per week". Hence it can be deduced that participants from rural areas ate deep fried/fried foods more frequently. On the other hand, it was found that less rural participants adhered to the recommendations for dairy products $(16.4 \%)$ as compared to urban (27.4\%). 
Table 2. Food frequency adherence.

\begin{tabular}{|c|c|c|}
\hline Food & Categories & Frequency/answer \\
\hline Dairy Products & 1: 2 - 3 times per day $\mathbf{2 1 \%}$ & 2 - 3 times per day \\
\hline Guideline: * & 0 : Less than 2 - 3 times per day $\mathbf{7 9 \%}$ & $\begin{array}{l}\text { Never/seldom, Less than once per week, Once per week, } \\
2 \text { - } 3 \text { times per week, Almost every day, once per day }\end{array}$ \\
\hline Carbohydrate rich foods & 1: 2 - 3 times per day $\mathbf{4 2 \%}$ & $2-3$ times per day \\
\hline Guideline: $a$ & 0 : Less than 2 - 3 times per day $\mathbf{5 8 \%}$ & $\begin{array}{l}\text { Never/seldom, Less than once per week, Once per week, } \\
2 \text { - } 3 \text { times per week, Almost every day, once per day }\end{array}$ \\
\hline Fish & 1: At least once per week $\mathbf{8 6} \%$ & $\begin{array}{l}\text { Once per week, } 2 \text { - } 3 \text { times per week, Almost every day, } \\
\text { Once per day, } 2 \text { - } 3 \text { times per day }\end{array}$ \\
\hline Guideline: ** & 0 : Less than once per week $\mathbf{1 4 \%}$ & Less than once per week, Never/seldom \\
\hline Chicken & 1: At least once per week $\mathbf{8 7 \%}$ & $\begin{array}{l}\text { Once per week, } 2 \text { - } 3 \text { times per week, Almost every day, } \\
\text { Once per day, } 2 \text { - } 3 \text { times per day }\end{array}$ \\
\hline Guideline: ** & 0 : Less than once per week $\mathbf{1 3} \%$ & Less than once per week, Never/seldom \\
\hline Red meats and meat products & 1: A couple of times per week or less $\mathbf{9 7 \%}$ & $\begin{array}{l}2 \text { - } 3 \text { times per week, Once per week, } \\
\text { Less than once per week, Never/seldom }\end{array}$ \\
\hline Guideline: ** & 0 : Everyday or almost every day $\mathbf{3 \%}$ & Almost every day, once per day, 2 - 3 times per day \\
\hline Vegetables - cooked and raw & 1: Everyday $65 \%$ & 2 - 3 times per day, Once per day \\
\hline Guideline: $b$ & 0 : Less everyday $\mathbf{3 5 \%}$ & $\begin{array}{l}\text { Almost every day, } 2 \text { - } 3 \text { times per week, Once per week, } \\
\text { Less than once per week, Never/seldom }\end{array}$ \\
\hline Fruits & 1: Everyday $\mathbf{5 4 \%}$ & 2 - 3 times per day, Once per day \\
\hline Guideline: $b$ & 0: Less than everyday $\mathbf{4 6 \%}$ & $\begin{array}{l}\text { Almost every day, } 2 \text { - } 3 \text { times per week, Once per week, } \\
\text { Less than once per week, Never/seldom }\end{array}$ \\
\hline Deep fried/fried foods & 1: Once per week and less $\mathbf{7 5 \%}$ & Never/seldom, Less than once per week, Once per week \\
\hline Guideline: $c$ & 0: More than once per week $\mathbf{2 5 \%}$ & $\begin{array}{l}2 \text { - } 3 \text { times per week, Almost every day, once per day, } \\
2 \text { - } 3 \text { times per day }\end{array}$ \\
\hline Sugar sweetened beverages & 1: Once per week and less $\mathbf{4 6} \%$ & Never/seldom, Less than once per week, Once per week \\
\hline Guideline: $f$ & 0 : More than once per week $\mathbf{5 4 \%}$ & $\begin{array}{l}2 \text { - } 3 \text { times per week, Almost every day, once per day, } \\
2 \text { - } 3 \text { times per day }\end{array}$ \\
\hline Cakes and pastries & 1: Once per week and less $\mathbf{4 7 \%}$ & Never/seldom, Less than once per week \\
\hline Guidelines: $c$ and $f$ & $0:$ More than once per week $\mathbf{5 3} \%$ & $\begin{array}{l}\text { Once per week, } 2 \text { - } 3 \text { times per week, Almost every day, } \\
\text { once per day, } 2 \text { - } 3 \text { times per day }\end{array}$ \\
\hline Pulses & 1: At least once per week $\mathbf{5 4 \%}$ & $\begin{array}{l}\text { Once per week, } 2 \text { - } 3 \text { times per week, Almost every day, } \\
\text { Once per day, } 2 \text { - } 3 \text { times per day }\end{array}$ \\
\hline Guideline: ** & 0 : Less than once per week $\mathbf{4 6 \%}$ & Less than once per week, Never/seldom \\
\hline
\end{tabular}

Food frequency items dichotomised into two groups with their percentages: "those adhering to the recommendations" and "others". Adapted from Dynesen et al. (2003). *Since no recommendation was mentioned in the WHO report concerning the frequency of dairy products, the USDA recommendation of 2 - 3 servings per day was used [13]. ** Since the recommendation (d) does not specify the frequency for these products, the dichotomisation is based on the fact that not eating meat as a main meal more than almost every day, leaves opportunity to eat pulses, fish and poultry as a main meal [5]. 1: "subjects adhering to the dietary guidelines"; 0: "others" a to f: as per WHO/Europe (2011) recommendations for a healthy lifestyle has the following dietary (refer to Section 3.2). 
Table 3. Sociodemographic variables with respective percentages.

(a)

\begin{tabular}{|c|c|c|c|c|c|c|c|c|c|c|c|c|c|}
\hline & & \multicolumn{2}{|c|}{ Gender } & \multicolumn{3}{|c|}{ Age } & \multicolumn{5}{|c|}{ Highest level of education } & \multicolumn{2}{|c|}{ Residence } \\
\hline & & Men & Women & $\begin{array}{l}\text { Young } \\
\text { adults }\end{array}$ & $\begin{array}{l}\text { Middle } \\
\text { aged }\end{array}$ & Elders & None & Primary & Secondary & Tertiary & Vocational & Urban & Rural \\
\hline & $n^{1}$ & 178 & 209 & 201 & 152 & 34 & 3 & 47 & 189 & 130 & 17 & 168 & 219 \\
\hline & Score $^{2}$ & \multicolumn{2}{|c|}{ Percentage $^{3}$} & \multicolumn{3}{|c|}{ Percentage } & \multicolumn{4}{|c|}{ Percentage } & & \multicolumn{2}{|c|}{ Percentage } \\
\hline \multirow{3}{*}{ Dairy Products } & 1: & & & & & & 0.0 & 21.3 & 14.3 & 30.8 & 29.4 & 27.4 & 16.4 \\
\hline & & & & & & & & & & & & & \\
\hline & 0: & & & & & & 100.0 & 78.7 & 85.7 & 69.2 & 70.6 & 72.6 & 83.6 \\
\hline $\begin{array}{l}\text { Carbohydrate } \\
\text { rich foods }\end{array}$ & 0: & & & & & & & & & & & & \\
\hline \multirow[b]{2}{*}{ Fish } & 1: & & & & & & & & & & & & \\
\hline & 0: & & & & & & & & & & & & \\
\hline \multirow{2}{*}{ Chicken } & 1: & & & & & & & & & & & & \\
\hline & 0: & & & & & & & & & & & & \\
\hline \multirow{2}{*}{$\begin{array}{l}\text { Red meat and } \\
\text { meat products }\end{array}$} & 1: & 94.9 & 98.6 & & & & & & & & & & \\
\hline & 0: & 5.1 & 1.4 & & & & & & & & & & \\
\hline \multirow{2}{*}{$\begin{array}{l}\text { Vegetable-cooked } \\
\text { or raw }\end{array}$} & 1: & & & & & & 100.0 & 63.8 & 72.5 & 53.1 & 70.6 & & \\
\hline & 0: & & & & & & 0.0 & 36.2 & 27.5 & 46.9 & 29.4 & & \\
\hline \multirow{3}{*}{ Fruits } & 1: & & & 50.3 & 54.3 & 76.6 & & & & & & & \\
\hline & & & & & & & & & & & & & \\
\hline & 0: & & & 49.7 & 45.7 & 23.5 & & & & & & & \\
\hline \multirow{2}{*}{$\begin{array}{l}\text { Deep Fried/Fried } \\
\text { foods }\end{array}$} & 1: & 67.4 & 81.8 & & & & & & & & & 16.7 & 31.1 \\
\hline & 0: & 32.6 & 18.2 & & & & & & & & & 83.3 & 68.9 \\
\hline \multirow{2}{*}{$\begin{array}{l}\text { Sugar sweetened } \\
\text { beverages }\end{array}$} & 1: & & & 32.7 & 57.2 & 73.5 & & & & & & & \\
\hline & 0: & & & 67.3 & 42.8 & 26.5 & & & & & & & \\
\hline & 1: & & & 41.0 & 53.6 & 55.9 & & & & & & & \\
\hline \multicolumn{14}{|l|}{ Cakes and pastries } \\
\hline & 0: & & & 59.0 & 46.4 & 44.1 & & & & & & & \\
\hline & 1: & & & 67.3 & 42.8 & 26.5 & & & & & & & \\
\hline \multicolumn{14}{|l|}{ Pulses } \\
\hline & 0: & & & 32.7 & 57.2 & 73.5 & & & & & & & \\
\hline
\end{tabular}


(b)

\begin{tabular}{|c|c|c|c|c|c|c|c|c|c|c|c|c|c|}
\hline & & \multicolumn{8}{|c|}{ Categorised occupation } & \multicolumn{4}{|c|}{ Family status } \\
\hline & & Professional & $\begin{array}{l}\text { Office } \\
\text { worker }\end{array}$ & $\begin{array}{l}\text { Service } \\
\text { worker }\end{array}$ & $\begin{array}{l}\text { Manual } \\
\text { worker }\end{array}$ & Un-employed & Student & Pensioner & $\begin{array}{c}\text { Self } \\
\text { employed }\end{array}$ & alone & $\begin{array}{l}\text { Small } \\
\text { family }\end{array}$ & $\begin{array}{l}\text { Medium } \\
\text { family }\end{array}$ & $\begin{array}{l}\text { Large } \\
\text { family }\end{array}$ \\
\hline & $n^{1}$ & 66 & 37 & 58 & 58 & 46 & 49 & 27 & 38 & 22 & 262 & 88 & 6 \\
\hline & Score $^{2}$ & \multicolumn{8}{|c|}{ Percentage $^{3}$} & \multicolumn{4}{|c|}{ Percentage } \\
\hline \multirow{3}{*}{ Dairy Products } & 1: & & & & & & & & & & & & \\
\hline & & & & & & & & & & & & & \\
\hline & 0: & & & & & & & & & & & & \\
\hline \multirow{2}{*}{$\begin{array}{l}\text { Carbohydrate } \\
\text { rich foods }\end{array}$} & 1: & & & & & & & & & 31.8 & 41.6 & 45.5 & 100.0 \\
\hline & 0: & & & & & & & & & 68.2 & 58.4 & 54.5 & 0.0 \\
\hline \multirow[b]{2}{*}{ Fish } & 1: & & & & & & & & & & & & \\
\hline & 0: & & & & & & & & & & & & \\
\hline \multirow{2}{*}{ Chicken } & 1: & & & & & & & & & & & & \\
\hline & 0: & & & & & & & & & & & & \\
\hline \multirow{2}{*}{$\begin{array}{l}\text { Red meat and } \\
\text { meat products }\end{array}$} & 1: & & & & & & & & & 86.4 & 98.8 & 98.9 & 100.0 \\
\hline & 0: & & & & & & & & & 13.6 & 1.9 & 1.1 & 0.0 \\
\hline \multirow{2}{*}{$\begin{array}{l}\text { Vegetable-cooked } \\
\text { or raw }\end{array}$} & 1: & 54.5 & 56.8 & 60.3 & 74.1 & 78.3 & 46.9 & 77.8 & 78.9 & & & & \\
\hline & 0: & 46.5 & 43.2 & 49.7 & 25.9 & 21.7 & 53.1 & 22.2 & 21.1 & & & & \\
\hline \multirow{3}{*}{ Fruits } & 1: & 42.4 & 36.1 & 50.0 & 50.0 & 71.7 & 51.0 & 74.1 & 65.8 & & & & \\
\hline & & & & & & & & & & & & & \\
\hline & 0: & 57.6 & 63.9 & 50.0 & 50.0 & 28.3 & 49.0 & 25.9 & 34.2 & & & & \\
\hline \multirow{2}{*}{$\begin{array}{l}\text { Deep Fried/Fried } \\
\text { foods }\end{array}$} & 1: & & & & & & & & & & & & \\
\hline & 0: & & & & & & & & & & & & \\
\hline \multirow{2}{*}{$\begin{array}{l}\text { Sugar sweetened } \\
\text { beverages }\end{array}$} & 1: & & & & & & & & & & & & \\
\hline & 0: & & & & & & & & & & & & \\
\hline \multirow{2}{*}{$\begin{array}{c}\text { Cakes and pas- } \\
\text { tries }\end{array}$} & 1: & 40.9 & 36.1 & 47.4 & 63.8 & 56.5 & 32.7 & 48.1 & 52.6 & & & & \\
\hline & 0: & 59.1 & 63.9 & 52.6 & 36.2 & 43.5 & 67.3 & 51.9 & 47.4 & & & & \\
\hline \multirow{2}{*}{ Pulses } & 1: & & & & & & & & & & & & \\
\hline & & & & & & & & & & & & & \\
\hline
\end{tabular}

${ }^{1} \boldsymbol{n}$ : the number of participants; ${ }^{2}$ score: 1: "those adhering to the guidelines"; 0: "others"; ${ }^{3}$ Percentages were generated column wise only for relationships that were significant for $p<0.05$. 
Age group was found to significantly $(p<0.05)$ influence adherence to the recommendations for sugar sweetened beverages; $32.7 \%$ amongst the young adults, $57.2 \%$ amongst the middle aged participants and $73.5 \%$ amongst the elders. It is to be noted that the population size for elders was considerably lower than that of young adults and middle aged and there was significance between intake of fruit and age group. Only half the population of young adults $(50.3 \%)$ and middle aged (54.5\%) adhered to the recommendations for fruits. Amongst the smaller population of elders, $76.6 \%$ adhered to the recommendation. The relationship between age and intake of pulses was also significant. Amongst the $54 \%$ of respondents which adhered to the recommendations, there were higher adherences amongst young adults (67.3\%) and middle aged (42.8\%). Although the population size was lower amongst elders, there was a much lower percentage which adhered $(26.5 \%)$. While higher percentages of middle aged and elders adhered to the recommendations $(53.6 \%$ and $55.9 \%$ respectively), a lower percentage of young adults had a score of $1(41.0 \%)$ although the population size in this category was the highest $(p<$ $0.05)$.

We also found that the level of education significantly influenced the dairy product intake. Amongst the 21\% that had the recommended " $2-3$ times per day", there was a higher percentage amongst those having tertiary education $(30.8 \%)$. Yet, a lower percentage $(14.3 \%)$ was reported amongst those having secondary education, despite a large population size of 189 respondents. Level of education also showed that relationship to vegetable intake was significant. Amongst all levels, there was a higher adherence $(65 \%)$ than non-adherence $(53 \%)$. Yet, almost half of the tertiary educated respondents $(46.9 \%)$ did not adhere to the recommendations.

Occupation showed a significant relationship to intake of fruits, vegetables and cakes and pastries. For vegetable intake, the adherence to the recommended "several times per day" was higher amongst manual workers $(74.1 \%)$ as compared to service workers $(60.3 \%)$ although both had the same population size. Comparatively lower percentages were seen amongst office workers $(56.8 \%)$ and selfemployed (78.9\%). Similar comparison could be made between unemployed (78.3\%) and students (46.9\%). Professionals which category had the larger number of respondents, showed $54.5 \%$ of adherence. Amongst all occupations, $50 \%$ or more adhered to the recommendations for fruit intake except for office workers and professionals, there were higher percentages of non-adherences of $63.9 \%$ and $57.6 \%$ respectively. The highest percentages of adherence were amongst unemployed $(71.7 \%)$ and self-employed (65.8\%). Occupation was significantly related to frequency of intake of cakes and pastries. The highest percentages of adherence were amongst manual workers (63.8\%) and unemployed (56.5\%). Students, office workers and professionals had lower percentages of adherence $(32.7 \%, 36.1 \%$ and $40.9 \%$ respectively). Results also showed significant relationships between family status and adherence to both the recommendations for carbohydrate rich foods and red meat and meat products. The number of respondents in each category of family status varied greatly and could not be compared accurately.

\section{Discussion}

With the aim of studying common socio-demographic factors with respect to eating practices in a multicultural society like Mauritius, we found significant relationships with adherence to the recommendations set by the WHO. It was found that socio-demographic factors amongst Mauritians indeed tend to influence some of the eating practices as depicted in other parts of the world. Only $21 \%$ of all participants claimed to consume the recommended 2 - 3 dairy products per day. Dairy products, a rich source of calcium, are required in increasing amounts at different stages of the lifecycle, yet no significant relationship was found between adherence to the recommended daily dairy product intake and the age group categories. In addition, it has been well documented that due to a decline in level estrogens, osteoporosis in postmenopausal women is common [14] yet in the present study, women did not appear to consume significantly more dairy products than men. Significantly higher levels of adherence to the recommended daily intake of dairy products were seen amongst respondents with tertiary level education and living in urban areas. Previously, Baranowski [7] has shown that for a food to be consumed it should be available in the environment and in the household. With both education and area of residence showing significant relationship to dairy product consumption, we can argue that the availability and the affordability of these products could have an influence on their consumption.

Carbohydrate rich foods such as breads, rice, potatoes and whole grains are good sources of energy and the Ministry of Health's mandate for 2009-2010 were to increase their consumption amongst the Mauritian population. From this study, we found a significant proportion of participants which adhered to the recommendations set by the WHO (2011); reporting to consume these foods "several times per day". No socio-demographic factors were found to influence the intake of these foods, although certain occupations tend to be more laborious and would require more carbohydrate rich meals. Manual workers rather showed significantly higher percentages of snacking on high fat foods (oily foods and pastries). A significant relationship was found nevertheless between carbohydrate rich foods and family status. Those living alone were found to adhere less to these recommendations; in- 
deed living alone may have some downsides as the inability to distribute household chores leaving less time to cook elaborate meals.

Fish and poultry are white meats and are generally considered healthy sources of proteins. The percentages of adherences to the recommendations for these foods were relatively high. Surprisingly, none of the socio-demographic factors assessed revealed a significant relationship to adherence to the recommendations for the consumption of fish. It would have been expected that with its abundance in the Mauritian fishing zones, there would be higher frequencies of fish consumption, yet respondents reported consuming poultry slightly more often than fish. Red meat other than being a source of protein is also a rich source of iron and many vitamins and minerals [15] but it is due to the fat content in red meat and meat products that they are not advised to be consumed regularly [16]. In our sample, a large proportion of the respondents adhered to the recommendations. Men reported consuming meat and meat products more frequently than women. Mauritius consists predominantly of Hindu and Muslim [17] and it was reported previously [15] that Hindus did not consume beef nor pork products and Muslims did not consume pork, which could explain the good adherence to the recommended intake. No significant relationships were found neither with level of education nor with occupation, and thus it can be suggested that the price of meat was not a factor for the consumption of meat and meat products.

Vegetables are rich sources of essential vitamins, minerals and dietary fibre. Their numerous health benefits have caused the WHO to recommend their consumption daily. SES was the main factor associated to vegetable consumption. Participants from low and middle SES had higher percentages for adherence to the recommended daily intake. Additionally, manual workers, unemployed, pensioners and self-employed workers also reported higher percentages of adherence to the recommendation. The same groups of respondents reported significantly lower mean consumption of OHMs as compared to professional, office workers, service workers and students. Furthermore, respondents with tertiary education and employed as professionals, office workers and students had the lower percentages of adherence to the recommended intake of vegetables. To this effect our data tend to oppose certain findings which reported higher consumption of vegetables with increasing levels of education [5]. It has been reported that vegetables were amongst the nutrient dense foods that were more costly and less likely to be consumed by lower income classes [18]. This shows that the price of vegetables in Mauritius did not hinder their consumption and that the frequent consumption of OHMs was a plausible reason as to why higher SES groups did not adhere to recommended daily intake of vegetables.
The frequent intake of vegetables and high mean intake of OHMs amongst service workers, showed that a considerable number of respondents were likely to make healthy eating choices even when eating OHMs.

Fruits are similar to vegetables with respect to their beneficial properties. More than half of the sample adhered to the WHO (2011) recommendations for eating fruits daily. The factors which showed significant relationship were age and occupation. Elders had highest percentage of adherence to the WHO (2011) recommendations. With age, adults require more fibre to prevent or alleviate problems of constipation which is why they may tend to eat more fibre rich foods. Respondents that were unemployed and pensioners had the highest percentage of adherence. It was reported that many respondents had home grown fruits and vegetables or kitchen gardens which could make these foods more available, yet no significant relationship was found between urban and rural inhabitants with consumption of fruits and vegetables unlike previously reported [5]. However, unemployed respondent and retired might have had more time to cultivate their own vegetables.

Deep fried and fried foods are rich in saturated fats and trans-fatty acids and their consumption has been advised to be consumed sparingly [16]. Three quarters of respondents reported consuming these foods "once per week or less". Amongst the remaining quarter, significant relationship was found between gender and place of residence. Men had a higher percentage of non-adherence to the recommendation as compared to women. Higher percentages were seen amongst inhabitants of rural areas. It was also found that there was a significantly higher mean consumption of OHMs amongst rural inhabitants for dinner. A plausible reason for these findings is that in Mauritius, inhabitants of rural area tend to lead a more traditional lifestyle, whereby cooking oily snacks and dishes such as curry is part of their of their culture. These foods are often made and sold by street vendors in rural areas and their consumption offers not only tasty food, but also social interaction with the seller and other buyers.

Sugar sweetened beverages are high in refined sugars thus being a high source of calories. Most contain many artificial flavouring and colourings. The WHO (2011) recommends that they should be consumed sparingly. We found that less than half of participants adhered to the recommendations. However, a higher percentage of young adults reported to consume these beverages "more than once per week" as compared to middle aged and elder respondents. The participants that were students fell into the young adult category. As such, similar findings were reported [19] which showed that students in Minneapolis consumed that regular soda 'several times per week'. The accessibility within the environment of young adults may be one possible factor while another may be less concern 
towards health at this age.

The results for cakes and pastries were in line with other reported results [20], which reported that younger, wealthier and educated Mauritians consumed a Western diet consisting of frequent consumption of cakes/pastries, meat and meat products. This present study reported similarities with respect to the relationship between age and cakes/pastries only. The lack of similar findings with respect to meat and meat products might have been due to either a change in dietary practice as previously reported [20] or it might be due to the difference in dietary sampling techniques used in these two studies.

Surprisingly, adherence to the recommendations for pulses showed significant relationship to age group. Elders reported eating pluses "less than once per week". Indeed elders, being more forgetful could have provided inaccurate results in the food frequency questionnaire, or more conceivably, many elders believe that pulses such as lentils elevate blood pressure and cause bloating, which is why they would consume them less frequently.

\section{Conclusion}

Eating practices are considered one of the important lifestyle determinants of health [5]. The present work has showed how sociodemographic factors are important contributors to certain eating practices and as such reflect the health status of the Mauritian society to a certain extent. Indeed, some sociodemographic factors were found to significantly influence eating practices. OHMs were consumed frequently by younger adult men and SES influenced the frequency of consumption of OHMs and vegetables. Young adults were found to consume sweetened beverages and cakes/pastries more frequently than other age groups. Oily foods were consumed mostly by middle aged men with secondary level education. Such eating patterns could predict future health concerns amongst these groups of individuals, therefore providing accurate targets for health interventions in future.

\section{Acknowledgements}

All participants who were involved in the study are gratefully acknowledged. The authors are also grateful to the University of Mauritius for financial support.

\section{REFERENCES}

[1] A. S. Anderson and S. E. Morris, "Changing Fortunes: Changing Food Choices," Nutrition \& Food Science, Vol. 30 , No. 1, 2000, pp. 12-15. doi:10.1108/00346650010304701

[2] D. L. Yadin, "The International Dictionary of Marketing: Over 2000 Professional Terms and Techniques," Kogan Page Publishers, London, 2002.

[3] O. Lee, "Internet Marketing Research: Theory and Prac- tice," Idea Group Inc, UK, 2001.

[4] D. B. Bills, "The Shape of Social Inequality: Stratification and Ethnicity in Comparative Perspective," Elsevier Ltd, UK, 2005.

[5] A. W. Dynesen, J. Haraldsdottir, L. Holm and A. Astrup, "Sociodemographic Differences in Dietary Habits Described by Food Frequency Questions-Results from Denmark," European Journal of Clinical Nutrition, Vol. 57, No. 12, 2003, pp. 1586-1597. doi:10.1038/sj.ejen. 1601728

[6] R. W. Jeffery, J. Baxter, M. Mcguire and J. Linde, “Are Fast Food Restaurants an Environmental Risk Factor for Obesity?" International Journal of Behaviour and Physical Activity, Vol. 3, No. 2, 2006. www.ijbnpa.org/content/3/1/2

[7] R. R. Watson, J. K. Gerald and V. R. Preedy, "Nutrients, Dietary Supplements, and Nutriceuticals: Cost Analysis Versus," Springer, New York, 2010, p. 58.

[8] Ministry of Health and Quality of Life Mauritius, NCD survey, "The Non-Communicable Diseases Survey: The Trends in Diabetes and Cardiovascular Disease Risk in Mauritius," 2009. www.gov.mu/portal/goc/moh/file/ncd/ncd-2009.pdf

[9] M. D. Schmeister, "Expanding Wallets and Waistlines: The Impact of Family Income on the BMI of Women and Men Eligible for the Earned Income Tax Credit," Health Economics, Vol. 18, No. 11, 2009, pp. 1277-1294. doi: $10.1002 /$ hec. 1430

[10] A. Knight and R. Warland, "The Relationship between Socio-Demographics and Concern about Food Safety Issues," Journal of Consumer Affairs, Vol. 38, No. 1, 2004, pp. 107-120. doi:10.1111/j.1745-6606.2004.tb00467.x

[11] A. M. Siega-Riz, B. M. Popkin and T. Carson, "Differences in Food Patterns at Breakfast by Sociodemographic Characteristics among a Nationally Representative Sample of Adults in the United States," Preventive Medicine, Vol. 30, No. 5, 2000, pp. 415-424. doi:10.1006/pmed.2000.0651

[12] R. V. Krejcie and D. W. Morgan, "Determining Sample Size for Research Activities," Educational and Psychological Measurement, Vol. 30, 1970, pp. 607-610.

[13] V. L. Fulgoni, P. J. Huth, D. B. Dirienzo and G. D. Miller, "Determination of the Optimal Number of Dairy Servings to Ensure Low Prevalence of Inadequate Calcium Intake in Americans," Journal of the American College of Nutrition, Vol. 23, No. 6, 2004, pp. 651-659.

[14] A. M. Sacco and W. E. Ward, "Revisiting Estrogen: Efficacy and Safety for Postmenopausal Bone Health," Journal of Osteoporosis, Vol. 2010, 2010, Article ID: 708931, pp. 1-8.

[15] A. H. Subratty and F. B. H. Gurib, “Consumers' Concern about Meat and Meat Products Quality Offered for Sale in Mauritius," Nutrition and Food Science, Vol. 33, No. 2, 2003, pp. 80-83. doi:10.1108/00346650310466664

[16] WHO, "12 Steps to Healthy Eating," WHO Regional Office for Europe, 2011.

www.euro.who.int/en/what-we-do/health-topics/disease-p 
revention/nutrition/a-healthy-lifestyle

[17] Central Statistics Office (MAURITIUS), "Under the Aegis of the Ministry of Finance and Economic Development," 2009. www.gov.mu

[18] Drewnowski, et al., "What Is Known about the Effectiveness of Economic Instruments to Reduce Consumption of Foods High in Saturated Fats and Other EnergyDense Foods for Preventing and Treating Obesity?" 2005 cited WHO 2006, July 2006, p. 7.

www.euro.who.int/data/assets/pdffile/0010/74467/E8890 9.pdf
[19] C. Arcan, M. Y. Kubik, J. A. Fulkerson and M. Story, "Sociodemographic Differences in Selected Eating Practices among Alternative High School Students," American Dietetic Association, Vol. 109, No. 5, 2009, pp. 823829.

[20] U. Uusitalo, J. Sobal, L. Moothoosamy, P. Chitson, J. Shaw, T. P. Zimme and J. Tuomilehto, "Dietary Westernisation: Conceptualisation and Measurement in Mauritius," Public Health Nutrition, Vol. 8, No. 6, 2005, pp. 608-619. doi:10.1079/PHN2004716 